Journal Home Page:

http://perlinguam.journals.ac.za
Per Linguam

A Journal for Language Learning Tydskrif vir Taalaanleer

\title{
CONCEPTUAL METAPHOR AND COMPREHENSION IN BUSINESS WRITING
}

\author{
Talita C Smit \\ University of Namibia
}

Recent research studies in cognitive linguistics (Gibbs, 1999; Kövecses, 2005; Lakoff, 1987; Lakoff \& Johnson, 1980; Lakoff \& Johnson, 1999) have demonstrated that metaphor is not merely a figure of speech. The findings of these studies have shown that metaphor influences a good deal of how people think as it comprises a specific mental, cross-domain mapping in the conceptual system (Balaban, 1999; Ibarretxe-Antuňanu, 1999; Lakoff, 2006; Lakoff \& Johnson, 1980). This article looks at whether employing different conceptual metaphors in different versions of the same business report will have an effect on reader comprehension. A small-scale research study was conducted with a group of second-year university students, in which they were given one of two texts concerning the recovery of the economy. Both texts were adapted from a newspaper report and seeded with metaphors and metaphoric expressions. The multiple-choice questions that followed aimed to determine to what extent the readers' comprehension and interpretation of the report were influenced by the different conceptual metaphors used. The findings indicate that language that served to introduce the sources or targets directly into the content did not necessarily have an effect on the processing of subsequent metaphors involving these concepts; however, it appeared that the surface patterns of metaphorical discourse did affect the inferences drawn about the different conceptual metaphors. It can thus be concluded that a specific metaphoric framework in written discourse does influence the interpretation of the content.

\section{Keywords}

conceptual metaphor; framing; metaphorical expressions; metaphorical patterns; metaphorical language; naming; perspective changing

\section{INTRODUCTION}

Metaphors can be regarded as systemic interrelations of multiple experiences which map one relatively stable 'domain' to another. It furthermore appears that the effective processing of metaphors is determined by their conventionality for the recipient. A conventional metaphor such as the economy is an ailing person, is processed directly and without the need for mapping between the source and the target. When a metaphor is not known, or maybe even less familiar to the reader, such as the economy is the globe which has not weathered the storm, mapping between the source and target is necessary before the metaphor can be processed further. According to Sopory and Dillard (2002), a substantial influence from metaphors can be expected in texts that are intended to persuade the reader - when the metaphor is novel, has a familiar target and is used early in the message. 
In order to test this supposition suggested by Sopory and Dillard, a study was conducted to determine the extent to which a reader would respond when reading a business report set in the framework of a specific conceptual metaphor. The context of the business report selected for this study was a discussion of economic trends in the last quarter of 2009 and the projected trends for the first quarter of 2010. Since the study was concerned with conceptual metaphors, decisions taken were informed by the theory of conceptual metaphor.

\section{CONCEPTUAL METAPHOR}

The theory of conceptual metaphor differs from many previous approaches, since it is primarily a theory of metaphorical cognition rather than of metaphorical language. According to Stefanowitsch (2006:64), metaphorical mappings such as anger is fire or the economy is an ill person are seen as instances of a psychological process of 'understanding and experiencing one kind of thing in terms of another' (Lakoff \& Johnson 1980:5). Stefanowitsch further states that metaphorical mappings are non-linguistic phenomena; therefore, what constitutes a metaphor is not any particular word or expression; it is 'the ontological mapping across conceptual domains' (Lakoff, 1993:208).

Steen (2008:231) suggests that three different functions of metaphor can be determined. The first is the lexical function. This means the filling of lexical and other gaps in the language system. This is also called naming. Secondly, Steen mentions the conceptual function of offering conceptual frameworks for concepts that require at least partial understanding, also called framing. Finally, there is the communicative function of producing an alternative perspective on a particular referent or topic, also called perspective changing. The current study was mainly interested in determining to what extent the perspective changing function of metaphor could be observed in the reading of business reports.

Steen continues by suggesting that further research needs to examine the relations between these three functions. He does, however, caution that a deliberate metaphor may be either conventional or novel. Furthermore, non-deliberate metaphor is not identical with conceptual metaphor. According to Steen, it is quite possible for people to use conventional metaphors very deliberately - 'use' being a cover term for both production and reception (2008:223). He continues that 'what was deliberately coded as metaphorical in production does not always have to be taken as such in reception, or [...] what is experienced as deliberately metaphorical in reception was not necessarily meant as such' (2008: 226).

It was thus decided to investigate what effect the use of a 'deliberately metaphorical' framework in a business report would have on its readers. One of the objectives was to determine whether an ontological mapping across two different conceptual domains, one conventional and one novel, would indicate a significant difference in the comprehension and interpretation of content information by readers. It was argued that the deliberate use of a metaphorical framework of disease would be familiar to the average reader as words, such as suffer and recovery, as well as the concept of disease as a source domain for a variety of target domains, is frequently used in reporting. The metaphor, the economy as the globe subjected to stormy weather, tends to be more novel and imaginative. Another objective was 
to determine whether language that serves to introduce the sources or targets directly into the content has an effect on the processing of subsequent metaphors involving these concepts.

These questions are rooted in the distinction that Steen (2008:223) proposes:

Deliberate metaphors ... involve the express use, in production and/or reception of another domain as a source domain for reviewing the target domain. Deliberate metaphor [use] is a relatively conscious discourse strategy that aims to elicit particular rhetoric effects. This is what distinguishes deliberate metaphor from all non-deliberate metaphor.

\section{THE STUDY}

According to Martin (2006:217), 'the minimal assumption [can be made] that language that serves to introduce the source or target concepts directly into the context may have an effect on the processing of subsequent metaphors involving these concepts.' He has made a further assumption that 'text that introduces a metaphor of the same basic types as the test metaphor into the context can be seen as introducing the ground of the metaphor'. Koller (2006:238) furthermore claims that 'ascertaining surface patterns of metaphorical expressions in discourse to some extent allows for inferences to be drawn about the conceptual metaphors that discourse is based upon'.

The first question in this study was thus whether language that serves to introduce the source or target concepts directly into the context might have an effect on the processing of subsequent metaphors involving these concepts. A second question asked was to what extent the surface patterns of metaphorical expressions in discourse would allow inferences to be drawn about the conceptual metaphors on which a specific discourse, a business report, is based. To answer these questions, it was decided to make use of a business report titled 'First quarter outlook on the country's retail sector positive' from one of the local daily newspapers, The Economist, of 10 February 2010

The text of this business report was adapted and two different versions of the original text were produced. The title for Text 1 was changed into Country's retail sector recovering. The text of the report was also reworked in the framework of the conceptual metaphor of the economy is a person who is ailing. The title for Text 2 was changed into Country's retail sector weathering the storm. The text of the report was reworked in the framework of the conceptual metaphor the economy is the globe subject to changes in the weather.

Since metaphor involves both conceptual mappings and individual linguistic expressions (Lakoff, 2006:192), both texts were seeded with 'metaphorical expressions, ... linguistic expressions (words, phrases or even sentences) that become the surface realisation of the cross-domain mapping in the conceptual metaphor' (2006:186). In this study, care was taken, when adding the different metaphorical expressions, that the essence of the original text was not changed, and that the metaphors used would correctly represent the information given in the original text.

After reading one of the reworked texts, the participants in the study had to choose the most appropriate option of three possible alternatives to ten multiple-choice questions. Care was taken when phrasing questions and answers to ensure that the metaphors added to the texts were not pointers to specific answers; however, the multiple-choice options of questions 1 to 
6 were structured in such a way that they related to the conceptual metaphorical frameworks of either Text 1 or Text 2. A third factually incorrect option was included.

Questions 7 to 10 served as control. In these questions only one of the answers was factually correct. These questions were also not related to any parts of the texts that were seeded with metaphor. The aim of this part of the test was to see whether the framework of conceptual metaphor used in each text was conducive to the overall understanding of the text. The consistency, or not, in the answers to these last four questions from both groups were also expected to indicate whether the previous answers were influenced by the conceptual framework or whether they could be regarded as randomly chosen.

\section{SAMPLE GROUP}

The participants in this small-scale study were not randomly sampled, but were 34 secondyear university students. They were all mother tongue speakers of an indigenous language. Their level of proficiency in English could be regarded as intermediate, as the majority of the participants changed to English as the language of instruction and learning in their Grade 4 year. No other variables, such as age and gender, were considered.

\section{FINDINGS}

In order to determine whether there was any significant difference between the responses to the two different texts, the data was statistically analysed. A test for the equality of means was conducted to look at the raw scores of the first six multiple-choice questions in the reading test. These questions were directly related to text areas where one of the two conceptual frameworks was employed.

Table 1: Equality of means: Text 1 and Text 2

\begin{tabular}{|c|c|c|c|}
\hline & \multicolumn{3}{|c|}{ t-test for Equality of Means } \\
\hline & $\mathrm{t}$ & df & $\begin{array}{c}\mathrm{Si} \\
\text { (2-tailed) }\end{array}$ \\
\hline Questions $1-6$ & -4.064 & 30 & $0.000 *$ \\
\hline
\end{tabular}

When the results of the t-test for the equality of means for the answers to questions 1 to 6 were statistically compared, it indicated that $\mathrm{t}=-4.064(p=0.000$, thus $<$ than 0.05$)$, indicating that there was a significant difference between the scores of the readers of Text 1 and Text 2 for questions 1 to 6 . As these were the questions related to the different conceptual frameworks of the economy is an ill person and the economy is a stormy globe, it seemed that the readers of Text 1 had been more consistent in their choices of the most appropriate answers to the questions. The choices that the readers of Text 2 had made in these 6 questions were much more random. It would be no more than an assumption to say that they were affected negatively in their comprehension of the text. It would possibly be more realistic to suggest that they accepted this more novel metaphorical framework in the reading passage, but were not necessarily influenced by it in their responses. It is, however, 
still remarkable that this group of readers often opted for the factually incorrect answer, while the readers of Text 1, in general, did not.

The following bar graph shows the choices made by the two reader groups:

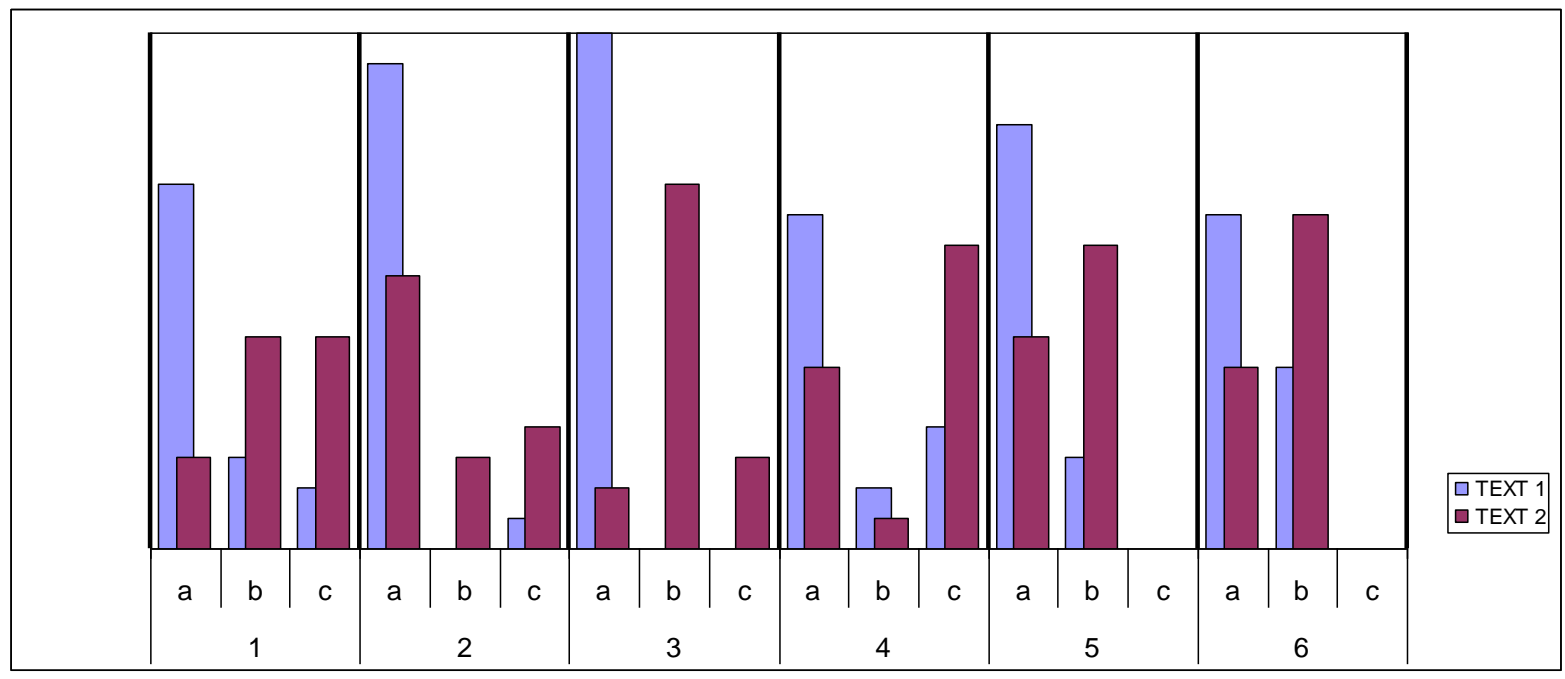

Figure 1: Multiple-choice answers for questions 1 to 6

Figure 1 clearly indicates that the participants who read Text 1 seemed to be more comfortable with the conceptual metaphor of the economy is an ailing person that was used as a framework for this text. A total of seven participants opted for those options to these six questions that were factually incorrect.

The high percentages of appropriate choices by the readers of Text 1 could possibly be related to what Boers (2006:553) has observed, namely that 'many polysemous lexical items occur more frequently in their derived figurative senses than in their original literal senses'. Boers continues that, in economic discourse, for example, 'words like prescription and remedy are not likely to refer to real medicine'. The readers of Text 1 were thus probably not even aware that the report was seeded with metaphorical expressions.

When the choices of the participants who read Text 2 were considered, their answers reflected a much more haphazard approach and they seemed not to have been helped by the conceptual framework of the metaphor, the economy as the stormy globe. In total, 24 participants opted for the answers to these six questions that were factually incorrect.

It thus seems that the framework of the conceptual metaphor, the economy is stormy, employed in Text 2, was less conducive to the comprehension and interpretation of the content than Text 1 in the framework of the conceptual metaphor, the economy is an ailing person. This might only be an assumption, because the participants who read Text 2 could have opted for the choice that reflects metaphorical expressions, such as suffer and recover, so commonly used that they are often not regarded as metaphors any longer. If that would have been the only explanation for the discrepancy, it is still interesting that such a large number of the readers of Text 2 opted for the factually incorrect answers, more that 3 times as many as those who read Text 1 . 
Table 2: Equality of means: Text 1 and Text 2: questions 7 to 10

\begin{tabular}{l|ccc} 
& \multicolumn{3}{|c}{ t-test for Equality of Means } \\
\hline & $\mathrm{t}$ & Df & Sig. (2-tailed) \\
\hline Questions 7-10 & .746 & 32 & 0.315 \\
\hline
\end{tabular}

When the results of the t-test for the equality of means for questions 7 to 10 were statistically compared, it showed that $\mathrm{t}=.746(p=0.315$ thus $>$ than 0.05$)$, indicating that there was not a significant difference between the scores of the participants who read Text 1 and the participants who read Text 2. It can thus be concluded that the majority of the participants did not experience apparent difficulty in comprehending the content of the texts as these last four questions were based on the factual information conveyed by the texts and were not influenced by metaphorical expressions related to either of the two conceptual metaphors employed in the rest of the texts.

The choices in the multiple-choice questions that served as control (questions 7 to 10) could be illustrated as follows:

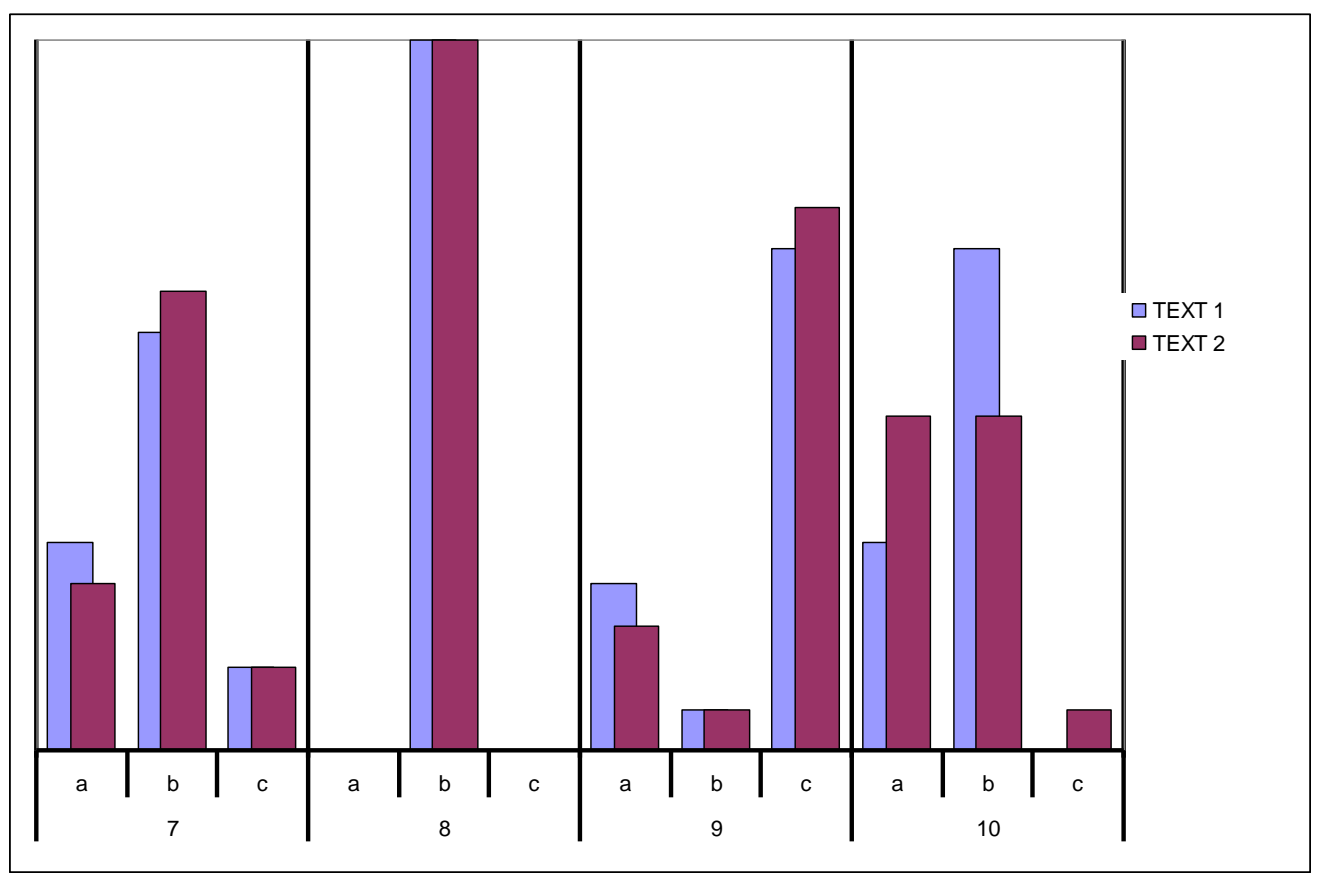

Figure 2: Multiple-choice answers for questions 7 to 10

Figure 2 indicates that the choices made by both groups of readers with regard to questions 7 to 10 corresponded to a great extent. The readers of the two different versions of the report seemed to have drawn the same inferences regarding the content of the report. 
A strange phenomenon, however, was picked up when six of the twelve readers of Text 2 who chose the most appropriate option for this question, regarded the metaphorical expression, overcast, as a positive sign for the recovery of the economy. This may probably be ascribed to a different perception on the part of English second language speakers who were involved in this study. Whereas overcast conditions might be seen as threatening in a country which receives much rain and which suffers from storms, overcast conditions are often a very positive sign in a drought-ridden country, thus reflecting a positive future outlook. At this stage, this is no more than an observation that needs to be researched before any definite conclusions can be drawn. It does, however, seem that differing cultural influences were responsible for the interpretation of the metaphor, overcast conditions.

\section{DISCUSSION}

When one considers that conceptual mapping involves, firstly, noticing a shared system of relations that hold in both the source and target domain and, secondly, placing objects from the two domains into correspondence on the basis of common roles in the shared relational structure, one can begin with a partial, structural mapping of components that play similar roles and later extend the mapping to import novel inferences from the source domain to the target (Coulson, 2001:165).

According to Gibbs (1999:146), there seems to be two ways in which metaphor might structure conceptual representation:

- The strong view: many concepts are not understood via own representations but by metaphorical connections to knowledge in different domains. In other words, people do not have independent, non-metaphorical concepts of aspects, such as love or the economy - concepts for love, and by implication the economy, are closely connected via metaphorical links to other, truly independent concepts such as that of journeys, e.g. The economy is going downhill.

- The weak view: people have well-developed, independent concepts, but these are often metaphorically linked to other concepts with similar structures. In other words, there is a distinct non-metaphorical concept of recovery, but this concept has well-established connections to distinct concepts from different domains of experience, like disease and bad weather, which are structured similarly in that both source and target domain share similar underlying attributes or relations.

It seems that research in cognitive linguistics as yet does not provide a firm basis for distinguishing between these two possibilities. Scholars such as Kövecses (2005) and Lakoff and Johnson (1999) tend to argue for the strong view. Gibbs (1999:146), however, feels that both the strong and weak views play a major role in people's mental representations of many, particularly abstract, concepts. The findings in this study seem to lean towards the weak view, as it seems that the non-metaphorical concepts of, for instance suffer and recover, were connected to both conceptual metaphors, the economy is an ill person and the economy is stormy, by some of the readers of the different versions of the same business report.

Finally, it is possible to agree with Boers (2006:566) that 'identifying metaphorical themes in actual discourse and categorising figurative expressions along those themes raises many 
methodological problems and is clearly not a matter of clear-cut choices'. Furthermore, as was found in this study, metaphorical themes sometimes can intersect. This is probably because the metaphorical elements represented in the illness metaphor are already so deeply entrenched in the frames of reference for many target domains that they can overlap with the metaphorical framework of, for instance, the weather.

\section{CONCLUSIONS}

The findings in this study seem to indicate that language that serves to introduce the sources or targets directly into the content does not necessarily have an effect on the processing of subsequent metaphors involving these concepts. It seems that readers of Text 1 did not connect the subsequent metaphorical expressions to the title as consistently as the readers of Text 1 did. It thus seems that a flexible conceptual metaphor, such as disease, enhances the readers' interpretation of the content in a specific report. The alternative seems to be that more novel metaphorical expressions do not seem to influence the reader as far as drawing inferences about the content of the report is concerned. A possible reason may be that metaphorical expressions relating to disease, such as recover, suffer, diagnose and prescribe, are so commonly used that they seem to have lost their 'metaphor-ness', whereas metaphorical expressions, such as a dark cloud and sunny skies, are figurative and less conventional.

Furthermore, the findings concerning the haphazardly chosen options to the multiple-choice questions 1 to 6 by the readers of Text 2 in this study, when compared to the choices made in Text 1 , indicate that the surface patterns of metaphorical expressions in discourse do seem to affect the inferences drawn about conceptual metaphors. The fact that both groups of readers chose similar options for the multiple-choice questions ( 7 to 10 - the control questions), but not for questions 1 to 6 , indicates the effect of the different metaphorical frameworks of the two texts on the drawing of inferences by the readers of these two business reports, even if at least only partly.

These findings are not conclusive and more research needs to be done to confirm them. They do, however, indicate that a specific metaphorical framework in written discourse, in this case a business report, does affect the interpretation, and possibly the comprehension, of the content presented.

\section{REFERENCES}

BALABAN, V. 1999. Self and agency in religious discourse: Perceptual metaphors for knowledge at a Marian apparition site. In Gibbs, RW (Jnr) \& GJ Steen (Eds), Metaphor in Cognitive Linguistics. Amsterdam: John Benjamins. 125-144.

BOERS, F. 2006. Metaphor awareness and vocabulary retention. Applied Linguistics, 21(4): 553-571.

COULSON, G. 2001. Semantic Leaps. Cape Town: Cambridge University Press.

GIBBS. R. (Jnr) 1999. Taking metaphor out of our heads and putting it into the cultural world. In Gibbs, RW (Jnr) \& GJ Steen (Eds), Metaphor in Cognitive Linguistics. Amsterdam: John Benjamins. 
IBARRETXE-ANTUŇANU, I. 1999. Metaphorical mappings in the sense of smell. In Gibbs, RW (Jnr) \& GJ Steen (Eds), Metaphor in Cognitive Linguistics. Amsterdam: John Benjamins. 29-45.

KOLLER, V. 2006. Of critical importance: Using electronic text corpura to study metaphor in business media discourse. In Stefanowitsch, A \& ST Gries (Eds), Corpus-based Approaches to Metaphor and Metonomy. Berlin: Mouton de Gruyter. 237-266.

KÖVECSES, Z. 2000. The scope of metaphor. In Barcelona, A (Ed), Metaphor and Metonymy at the Crossroads: A Cognitive Perspective. Berlin: Mouton de Gruyter. 79-92.

KÖVECSES, Z. 2005. Metaphor in culture universality and variation. Cambridge: Cambridge University Press.

LAKOFF, G. 1987. Women, fire and dangerous things: What categories reveal about the mind. Chicago: University of Chicago Press.

LAKOFF, G. 1993. The contemporary theory of metaphor. In Ortony, A (Ed), Metaphor and Thought ( $2^{\text {nd }}$ edition). Cambridge: Cambridge University Press. 202-251.

LAKOFF, G. 2006. Conceptual metaphor. In Geeraerts, D (Ed), Cognitive linguistics: Basic readings. Berlin: Mouton de Gruyter. 185-237.

LAKOFF, G \& M JOHNSON. 1980. Metaphors we live by. Chicago: The University of Chicago Press.

LAKOFF, G \& M JOHNSON. 1999. Philosophy in the Flesh. New York: Basic Books.

MARTIN, JH. 2006. A corpus-based analysis of context effects on metaphor comprehension. In Stefanowitsch, A \& ST Gries (Eds), Corpus-based Approaches to Metaphor and Metonomy. Berlin: Mouton de Gruyter. 214-236.

SOPORY, P \& J DILLARD. 2002. The persuasive effects of metaphor: A metaanalysis. Human communication survey: A turning tide among teenagers. Cape Town: HSRC Press.

STEEN, G. 2008. The paradox of metaphor: Why we need a three-dimensional model of metaphor. Metaphor and Symbol, 23(4):213-241.

STEFANOWITSCH, A. 2006. Words and their metaphors: A corpus-based approach. In Stefanowitsch, A \& ST Gries (Eds), Corpus-based approaches to metaphor and metonomy. Berlin: Mouton de Gruyter.

\section{BIOGRAPHICAL NOTE}

The author, holding a $\mathrm{PhD}$ from the University of Stellenbosch, is Head of the English Section, University of Namibia. Fields of interests are cognitive linguistics, academic and critical literacy. Three peer-reviewed articles on research in these areas were published in local academic journals; papers were delivered at seven international conferences. E-mail address: tcsmit@unam.na or smittalita@yahoo.com 


\section{ADDENDUM A}

\section{Report from The Economist, 10 February 2010.}

\section{First quarter outlook on the country's retail sector positive}

The economic recession that started in 2009 is far from over yet, but the outlook for the first quarter of 2010 remains positive for businesses in the country's retail sector a Retail Business survey has shown.

According to the IJG retail Business Survey which was released recently, major investments are lined up in the first quarter of 2010, while the greater majority of retailers will neither reduce nor increase their employees.

While $37 \%$ of businesses interviewed for the purposes of the study do not expect any improvement or worsening of business conditions, $42 \%$ expect that business conditions will be better than in the third quarter of 2009. Clothing retailers, food and beverage retailers experienced a good period from September to December 2009, while stationery and pharmaceutical retailers experienced worse conditions compared to the previous quarter of the same year. The survey shows that $53 \%$ of respondents projected a better revenue collection in the first quarter of this year, while $35 \%$ of the respondents expect no changes in revenue collection trends. Despite the positive business situation for most of the retailers, the industry was bothered by major challenges, some of which include inflation, skills shortages and macroeconomic uncertainty.

"Crime tops the list of major challenges that the industry is facing, being recorded by nine out of 20 retailers. Crime, especially theft, has led to losses of around N\$5.1 million for the companies surveyed during the last three months of 2009. The theft is mostly attributed to the difficult economic times and the large volumes of customers who frequent retail outlets. Some retailers, however, were not sure if their own employees were involved in these losses," the report states. Retailers also faced other challenges including customs, electricity supply, transportation, trade regulations and corruption.

The study, which was released recently, was conducted by the Institute for Public Policy Research (IPPR) and focuses on business climate, sales and supplies, capacity and innovation and financial performance within the retail sector. The IPPR conducted interviews with 20 leading businesses in the retail sector.

\section{READING PASSAGE 1}

\section{Country's retail sector recovering}

The ailing economy of 2009 is far from healed yet, but the prognosis for the first quarter of 2010 shows positive indications for recovery for businesses in the country's retail sector, a Retail Business survey has diagnosed.

According to the IJG Retail Business Survey which was released recently, major investments are prescribed for the first quarter of 2010, while the greater majority of retailers will neither reduce nor increase their employees. 
While $37 \%$ of businesses interviewed for the purposes of the study do expect stable business conditions, $42 \%$ expect that business conditions will be recovering in the third quarter of 2009. Clothing retailers, food and beverage retailers experienced a good period from September to December 2009, while stationery and pharmaceutical retailers experienced worse conditions compared to the previous quarter of the same year. The survey shows that $53 \%$ of respondents diagnosed a better revenue collection in the first quarter of this year, while $35 \%$ of the respondents expect no changes in revenue collection trends. Despite the positive business prognosis for most of the retailers, the industry was plagued by major challenges some of which include inflation, skills shortages and macroeconomic uncertainty.

"Crime tops the list of major social diseases that the industry is facing, being recorded by nine out of 20 retailers. Crime, especially theft, has led to losses of around $\mathrm{N} \$ 5.1$ million for the companies surveyed during the last three months of 2009. The theft is mostly attributed to the economic hardships and the large volumes of customers who frequent retail outlets. Some retailers, however, were not sure if their own employees were involved in these losses," the report states. Retailers also need remedies for other challenges including customs, electricity supply, transportation, trade regulations and corruption.

This diagnostic study which was released recently, was conducted by the Institute for Public Policy Research (IPPR) and focuses on business ailments, sales and supplies, capacity and innovation and financial performance within the retail sector. The IPPR conducted interviews with 20 leading businesses in the retail sector.

\section{Country's retail sector is weathering the storm}

The stormy economic recession of 2009 is far from weathered yet, but the forecast for the first quarter of 2010 remains positive for businesses in the country's retail sector, a Retail Business survey has shown.

According to the IJG retail Business Survey which was released recently, the sky is blue for major investments in the first quarter of 2010, while the greater majority of retailers will neither reduce nor increase their employees.

While $37 \%$ of businesses interviewed for the purposes of the study do not expect any stormy weather or worsening of business climate, $42 \%$ expect blue skies for business conditions and better improvements than in the third quarter of 2009. Clothing retailers, food and beverage retailers experienced a sunny period from September to December 2009, while stationery and pharmaceutical retailers experienced overcast conditions compared to the previous quarter of the same year. The survey shows that $53 \%$ of respondents forecasted a better revenue collection in the first quarter of this year, while $35 \%$ of the respondents expect stable weather in revenue collection trends. Despite the positive business climate for most of the retailers, the industry was threatened by major challenges, some of which include inflation, skills shortages and macro-economic uncertainty.

"Crime as the darkest cloud that hangs over the industry is being recorded by nine out of 20 retailers. Crime, especially theft, has led to losses of around $\mathrm{N} \$ 5.1$ million for the companies surveyed during the last three months of 2009. The theft is mostly attributed to the dark economic times and the large volumes of customers who frequent retail outlets. Some retailers, however, were not sure if their own employees were involved in these losses," the report states. 
Retailers also faced other challenges including customs, electricity supply, transportation, trade regulations and corruption.

The study which was released recently, was conducted by the Institute for Public Policy Research (IPPR) and focuses on business climate, sales and supplies, capacity and innovation and financial performance within the retail sector. The IPPR conducted interviews with 20 leading businesses in the retail sector.

\section{MULTIPLE-CHOICE QUESTIONS}

a. Draw a circle around the answer that you find to be THE MOST APPROPRIATE.

b. Please say why you have chosen that answer.

1. In 2009 the retail sector of the country:
a. suffered
b. experienced dark times
c. showed progress

Give a reason for your answer:

2. The outlook for the first quarter of 2010 indicates that
a. the economy will recover
b. economic dark times will clear up
c. the economy will stay the same

Give a reason for your answer:

3. $37 \%$ of businesses expect
a. the economic conditions to stay stable
b. no worsening of the economic situation
c. nothing to happen

Give a reason for your answer:

4. In the first quarter of 2010 , the sales of stationery and pharmaceuticals
a. suffered
b. were not calm
c. went very well

Give a reason for your answer:

5. The industry
a. suffered major challenges
b. found the major challenges frightening
c. was not upset by the major challenges

Give a reason for your answer:

6. 9 out of 20 retailers see crime as:
a. something that affects society negatively
b. something that prevents them from seeing success
c. something that is not threatening at all

Give a reason for your answer:

7. Retailers say that theft can be because
a. the economy is suffering
b. the negative economic times we are living in
c. the greediness of customers

8. Crime is:
a. the only challenge retailers face
b. the biggest challenge retailers face
c. the smallest challenge retailers face 
Give a reason for your answer:

9. The study that was conducted by IPPR DID NOT LOOK at:
a. the ability of retailers to think of new ways to be successful
b. the relationship between the availability of goods and the sale of goods
c. customer complaints

Give a reason for your answer:

10. All in all the IPPR report shows

a. little confidence in the economic future

b. a realistic picture of the state of the economy at the beginning of 2010

c. no hope for the country

Give a reason for your answer: 